\title{
SEMELHANÇAS E DIFERENÇAS ENTRE O TRABALHO DO DIRIGENTE DA PEQUENA EMPRESA E DO ADMINISTRADOR DAS CORPORAÇÕES
}

Daniela Rosim ${ }^{1}$

Edmundo Escrivão Filho ${ }^{2}$

Marcelo Nagano ${ }^{2}$

Luiz Philippsen Jr. ${ }^{3}$

${ }^{1}$ Universidade Federal de Goiás

${ }^{2}$ Escola de Engenharia de São Carlos / Universidade de São Paulo

${ }^{3}$ Universidade Federal de Alagoas 


\section{SEMELHANÇAS E DIFERENÇAS ENTRE O TRABALHO DO DIRIGENTE DA PEQUENA EMPRESA E DO ADMINISTRADOR DAS CORPORAÇÕES}

Resumo: Este artigo se propõe a oferecer uma resposta mais concludente ao debate sobre a semelhança ou diferença entre o trabalho do dirigente da pequena empresa e o trabalho do administrador das corporações, por meio de cinco casos de pequenas empresas brasileiras e dois casos de pequenas empresas internacionais. Esses estudos são comparados com o estudo clássico de Mintzberg (1973). Todos os casos apresentados neste artigo replicam o mesmo método de coleta de dados - observação estruturada - utilizado por Mintzberg (1973), permitindo comparações e análises, com suporte da estatística descritiva. Conclui-se que o trabalho do dirigente da pequena empresa apresenta mais aspectos similares ao trabalho do executivo das corporações, diferenciando-se apenas no que se refere a brevidade e fragmentação das atividades e preferência por não agendamentos e improvisos. As divergências podem ser compreendidas por meio das especificidades de gestão das pequenas empresas.

Palavras-chave: Pequenas empresas. Trabalho do dirigente da pequena empresa. Administrador das corporações. Especificidades de gestão das pequenas empresas.

\section{Introdução}

Desde que Carlson (1951) estudou, pela primeira vez de maneira sistemática, o trabalho do executivo, inaugurou-se uma longa e vasta tradição de pesquisa sobre a natureza do trabalho do administrador das corporações e suas características essenciais, ainda não observada nos estudos sobre a natureza do trabalho do dirigente da pequena empresa (O'GORMAN; BOURKE; MURRAY, 2005; TENGBLAD; VIE, 2012).

As pequenas empresas contribuem significantemente para o crescimento econômico das nações (BRUCE et al., 2009), sendo agentes de sustentabilidade do volume de negócios e fomentando a diversificação da economia de muitos países (COPPA; SRIRAMESH, 2013). No entanto, Storey $^{1}$ (1986 apud FULLER-LOVE, 2006, p. 177) destaca que elas não são "pequenas grandes empresas", mas um setor específico que requer teorias específicas para seu gerenciamento e, por isso, é importante e necessário que sejam aprofundadas as pesquisas que buscam identificar técnicas específicas de gestão para tal setor.

Há estudos que buscam entender a natureza do trabalho do dirigente da pequena empresa, porém, ainda apresentam resultados irresolutos sobre o assunto, indicando apenas a existência de aspectos similares e diferentes do trabalho do administrador das corporações (FLORÉN; TELL, 2003; O'GORMAN; BOURKE; MURRAY, 2005).

Portanto, entende-se que a literatura sobre a natureza do trabalho do dirigente da pequena empresa ainda não foi capaz de responder a seguinte pergunta: o trabalho do dirigente da pequena empresa apresenta mais aspectos semelhantes ou mais aspectos diferentes do trabalho do administrador das corporações? A fim de responder essa pergunta, este artigo apresenta e discute cinco casos de pequenas empresas brasileiras, mais dois estudos da mesma natureza conduzidos com dirigentes proprietários em outros países,

${ }^{1}$ STOREY, D. J. Entrepreneurship and the new firm. London: Croom Helm, 1986. 
comparando-os com o estudo realizado por Mintzberg (1973) para descrever o trabalho do administrador das corporações. Além disso, este artigo compara o trabalho do dirigente das pequenas empresas brasileiras com o trabalho do dirigente das pequenas empresas de outros países.

O trabalho de Mintzberg (1973) foi um marco nos estudos relacionados à descrição do trabalho do administrador das corporações, tendo sido revisitado e atualizado por autores como Kurke e Aldrich (1983) e Tengblad (2006). Tengblad (2006), por exemplo, reconduziu o mesmo estudo 30 anos depois chegando à conclusão que houve alterações na forma do administrador trabalhar, principalmente em razão do advento tecnológico, no entanto, a essência do trabalho do administrador praticamente não sofreu alterações.

O desenvolvimento de programas de gerenciamento é amplamente aceito como meio de aperfeiçoar a competitividade das empresas e a economia como um todo (FULLER-LOVE, 2006). Embora no passado a educação e o treinamento gerencial tivessem como foco somente as corporações, percebe-se um aumento da consciência sobre a necessidade do desenvolvimento de técnicas gerenciais voltadas à pequena empresa. No entanto, mesmo com esse aumento da consciência de necessidade, ainda é escasso o desenvolvimento de teoria de gerenciamento específica para pequenas empresas, revelando assim, uma carência de estudos com esse foco.

\section{Referencial Teórico}

O trabalho de Mintzberg (1973) é considerado um exemplo de método a ser seguido no que se refere à tradição em pesquisas sobre o trabalho do administrador das corporações. Tal tendência é também identificada nos estudos sobre a natureza do trabalho do dirigente da pequena empresa. São muitos os estudos que se utilizam desse referencial e/ou replicam a sua investigação, como por exemplo Kurke e Aldrich (1983), Florén e Tell (2003), O'Gorman, Bourke e Murray (2005), Gabrielsson e Tell (2009), Florén e Tell (2007), Andersson e Tell (2009), Andersson e Florén (2011), Florén e Tell (2012) e Tell e Gabrielsson (2013).

\subsection{O trabalho do administrador das corporações}

Mintzberg (1973) foi o criador da abordagem dos papéis, também conhecida como escola das atividades diárias de trabalho, a qual pertence ao campo de estudo sobre como os gerentes gastam o seu tempo (STEWART, 1976; 1979). Essa abordagem advém dos estudos de Carlson (1951), também sofrendo influência de pesquisadores como Chester Barnard e Hebert Simon (ESCRIVÃO FILHO; MENDES, 2010).

Para Mintzberg (1973), a administração há muito tempo não enfrentava seriamente a pergunta fundamental: o que realmente fazem os administradores? Para o autor, até a década de 1970, falar sobre o trabalho do administrador remetia diretamente, e quase que exclusivamente, às funções apresentadas por Henri Fayol no começo do Século XX. Inaugurando a abordagem dos papéis, Mintzberg (1973) discordou de Fayol no que se refere à forma de descrição do trabalho do administrador. Os autores clássicos da Administração, dentre eles Fayol, apresentavam publicações de caráter prescritivo, com orientações do tipo "deve ser", sem base empírica; para Mintzberg (1973), esses estudos

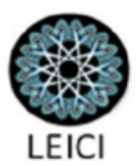


tinham baixa validade explicativa, pois não se baseavam na observação do trabalho real do administrador.

Várias pesquisas foram realizadas por Mintzberg entre 1960 e 1970 - como por exemplo, Mintzberg (1975; 1994a, 1994b e 2010) - muitas delas, inclusive, baseando-se especificamente na observação estruturada.

Mintzberg (1973) estudou cinco diretores-presidentes de grandes e médias empresas norte-americanas. Enquanto foram observadas atentamente as atividades do executivo, também foram realizadas anotações em formulários pré-planejados e em diários. Posteriormente foi publicado o artigo "Trabalho do administrador: folclore e fato" (Mintzberg, 1975), onde o autor menciona que as conhecidas descrições dos autores da abordagem do processo sobre o trabalho do administrador são verdadeiros folclores e não correspondem a realidade do que os administradores fazem na prática. Para Mintzberg (1973; 1975), o trabalho do administrador é muito mais fragmentado e breve do que o que foi descrito por Fayol; os administradores trabalham mais com outras pessoas e pouco tempo é despendido em tarefas solitárias. Para Mintzberg (1975; 1994a), o que o administrador faz é simplesmente responder às pressões do dia a dia.

Mintzberg (1973) propôs uma explicação para o desempenho das atividades do administrador baseada em dez papéis componentes do seu cargo, divididos em:

- $\quad$ interpessoais (o administrador se mantém em contato com as áreas da empresa e com seus subordinados sendo representante, líder e interligando as áreas e pessoas);

- informacionais (o administrador fica atento as informações internas e externas e age como um monitor e porta voz); e

- decisionais (o administrador, baseado nas informações que ele possui, toma decisões, estabelece objetivos, distribui recursos e lida com conflitos).

Como forma de validar a teoria inaugurada por Minztberg (1973), Kurke e Aldrich (1983) realizam uma réplica, dez anos depois do estudo original, alegando que a réplica diminui os argumentos contrários e aumenta a validade do estudo original. Os autores estudaram quatro executivos dos Estados Unidos, também durante uma semana cada um. Florén e Tell (2003) observam que Kurke e Aldrich (1983) não falaram do número de funcionários das organizações cujos executivos foram investigados, no entanto, pode-se considerar que tratavam-se de organizações com mais de cem funcionários, de acordo com os fatos revelados no estudo.

O trabalho de Kurke e Aldrich (1983) confirma a solidez dos resultados de Mintzberg (1973), reforçando a imagem dos gerentes operando em um ambiente de trabalho caracterizado pela fragmentação, brevidade das atividades, concentração no meio de vida e dependência de outros para iniciar os contatos. Vale destacar que as observações de Kurke e Aldrich (1983), além de realizadas uma década depois de Mintzberg, foram conduzidas em diferentes organizações e regiões, e por observadores diferentes. Sendo assim, créditos devem ser dados ao trabalho Mintzberg (1973), não somente pela validade das generalizações que ele trouxe, mas também pela clareza com que os resultados são apresentados (KURKE; ALDRICH, 1983).

Na mesma tendência de validar os dados de Mintzberg (1973) e verificar as mudanças ocorridas na forma de gerenciamento, Tengblad (2006) fez uma nova réplica do estudo 
original, trinta anos mais tarde. Como conclusão o autor identificou mudanças na forma de trabalho do administrador, no entanto, destaca que também há semelhanças significativas entre a nova e a velha forma de trabalho, e que essas semelhanças demonstram que as alegações do surgimento de um trabalho de gestão radicalmente diferente do que ocorria nos anos anteriores são exageradas.

Em vez do surgimento de uma gestão radicalmente diferente, a teoria evidencia que as novas práticas de trabalho são combinadas com as práticas mais velhas, formando um complexo de trabalho específico (TENGBLAD; VIE, 2012; SIMARD; RICE; 2006; TONIDANDEL; BRADDY; FLEENOR, 2012; MINTZBERG, 2010). A realidade desses estudos, no entanto, se aplica ao contexto das corporações.

\subsection{Especificidades de gestão da pequena empresa}

Tão clara quanto a afirmativa de que "crianças não são pequenos adultos" (DANDRIDGE, 1979), a pequena empresa tampouco deve ser interpretada como uma "pequena grande empresa" (WELSH; WHITE, 1981). Desta forma, não é possível adotar, de forma incontestável, a teoria de gerenciamento das corporações, pois a pequena empresa tem diferenças de estrutura organizacional e gestão que faz com que exista a necessidade do desenvolvimento de teoria específica para esse setor (WELSH; WHITE, 1981; JULIEN, 1993; LEONE, 1999; TORRÈS, 2004).

As pequenas empresas podem ser consideradas únicas em diversas dimensões e características (AREND, 2014). Ela apresenta carência de recursos organizacionais, como falta de poder de compra, baixa capacidade de influenciar os fornecedores, escassez de recursos internos como, por exemplo, o tempo disponível dos dirigentes e mão de obra (ADAMS, KHOJA, KAUFFMAN, 2012; ALBUQUERQUE et al., 2016; ESCRIVÃO FILHO, et al., 2017).

Para muitos estudiosos constituir-se pequena empresa era apenas uma etapa em direção ao crescimento. Da mesma forma, ter sucesso seria, portanto, crescer e se tornar grande. Sendo assim, as diferenças estariam nos aspectos quantitativos como faturamento, vendas, quantidade de funcionários, fatia dominante do mercado, dentre outros, do que propriamente particularidade de seus aspectos gerenciais. Essa visão recebeu críticas de autores como Dandridge (1979) e Julien (1993).

Para Olsen, Legg e Hasle (2012) as pequenas empresas são normalmente caracterizadas como tendo insuficiência financeira e de gestão de recursos. O proprietário da pequena empresa é muitas vezes o gerente e tem que lidar com um número de diferentes funções administrativas e de gestão, tais como vendas, planejamento, recursos humanos, finanças, contabilidade e faturamento. Também na pequena empresa as questões de disponibilidade de crédito e os custos de obtenção são diferentes, tornando-as mais dependentes dos bancos em função de indisponibilidade de acesso a dívida pública e mercado de ações, fato que também interfere na sua forma de gestão (DIETRICH, 2012).

Devido as especificidades acima mencionadas, Escrivão Filho (2006) e Boswell (2014) destacam a importância da análise qualitativa da pequena empresa por meio de suas especificidades. Considerando a proximidade do dirigente aos seus funcionários, Escrivão Filho (2006) acredita que, se por um lado ela possibilita um maior entusiasmo pelo trabalho, por outro, pode gerar a ausência de regras e o paternalismo. O mesmo pode ocorrer com as

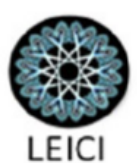


áreas ligadas à estrutura organizacional, estratégia, tomada de decisão, gestão da informação, relacionamento com o cliente, dentre outras.

Assim, para a compreensão da pequena empresa é necessário o conhecimento profundo de suas especificidades e características peculiares (LEONE, 1999). Torrès (2004) apresenta os conceitos de especificidades chamando-as de proximidade hierárquica, proximidade funcional, proximidade dos sistemas de informações e proximidade temporal, apresentados no Quadro 1.

Quadro 1 - As especificidades de gestão da pequena empresa (TORRÈS, 2004)

\begin{tabular}{|c|c|}
\hline $\begin{array}{l}\text { Proximidade } \\
\text { hierárquica }\end{array}$ & $\begin{array}{l}>\text { Personalização da gestão concentrada na pessoa do proprietário-dirigente } \\
>\text { Necessidade de uma quantidade menor de unidades ou funções } \\
>\text { Estrutura hierárquica simples }\end{array}$ \\
\hline $\begin{array}{l}\text { Proximidade } \\
\text { funcional }\end{array}$ & $\begin{array}{l}\text { Divisão do trabalho não é intensiva } \\
\text { Funções integradas e altamente conectadas } \\
\text { Gerenciamento baseado na versatilidade dos funcionários } \\
\text { Dirigente proprietário e os funcionários da empresa estão permanentemente em } \\
\text { contato para a resolução de problemas } \\
\text { A proximidade entre os funcionários e a gerencia desencoraja a divisão do } \\
\text { trabalho. } \\
\text { Os mecanismos de coordenação são restringidos pela proximidade entre os } \\
\text { funcionários e o dirigente }\end{array}$ \\
\hline $\begin{array}{l}\text { Proximidade } \\
\text { dos sistemas } \\
\text { de } \\
\text { informação }\end{array}$ & $\begin{array}{l}\text { Sistemas de informações simples } \\
\text { Preferência pelo contato direto e verbal } \\
\text { Os sistemas de informações externas também são simples por conta do mercado } \\
\text { restrito geograficamente } \\
\text { D Dirigente proprietário dialoga direto com os funcionários, fornecedores e clientes } \\
\text { Proximidade física do dirigente proprietário e do mercado de atuação da empresa } \\
\text { Ps informações são obtidas por meio dos relacionamentos informais e dos } \\
\text { contatos interpessoais que não são institucionalizados e são desestruturados }\end{array}$ \\
\hline $\begin{array}{l}\text { Proximidade } \\
\text { temporal }\end{array}$ & $\begin{array}{l}\text { O processo de tomada de decisão dos dirigentes proprietários é considerado } \\
\text { intuitivo } \\
\text { Dirigente toma decisão sem depender de informações de modelos formais } \\
\text { Estratégia é implícita e muito flexível, sendo modificada a qualquer hora de } \\
\text { acordo com a vontade do dirigente }\end{array}$ \\
\hline
\end{tabular}

A partir das especificidades de gestão da pequena empresa, pode-se compreender muitas outras características desse setor, principalmente aquelas que se referem ao gestor principal, ou seja, o seu dirigente.

\subsection{0 trabalho do dirigente da pequena empresa}

A fim de entender melhor o que faz o dirigente da pequena empresa, alguns estudos são examinados nesta subseção. Os estudos de Florén e Tell (2003) e de O'Gorman, Bourke e Murray (2005) representam casos de dirigentes de pequenas empresas no contexto internacional. Já Gromik (2011) e Rosim (2013) estudaram casos do dirigente da pequena empresa no Brasil. 
Florén e Tell (2003) se propõem a comparar os resultados sobre o trabalho do dirigente da pequena empresa com o trabalho do administrador nas corporações. Os autores investigaram seis dirigentes proprietários de pequenas empresas na Suécia, sendo que essas empresas tinham de 17 a 43 funcionários. Ao todo foram seis semanas de observação estruturada, conforme método usado por Mintzberg (1973). Como conclusão, Florén e Tell (2003) colocam que o trabalho do dirigente da pequena empresa apresenta semelhanças e diferenças em relação ao trabalho do administrador das corporações e que as atividades mais comuns para os dirigentes foram os períodos na mesa de trabalho, enquanto que para os executivos foram as atividades planejadas. Apesar dos autores chegarem a conclusão de que há semelhanças e diferenças na natureza do trabalho dos administradores e dirigentes, os mesmos não apontam se predominam semelhanças ou diferenças, quais são elas e porque elas ocorrem.

O'Gorman, Bourke e Murray (2005) realizaram uma investigação com dez dirigentes proprietários de pequenas empresas em crescimento na Irlanda. Essas empresas representavam 10 das 45 pequenas empresas que mais cresceram no período do estudo e todas tinham menos de 250 funcionários. $O$ estudo buscava verificar se o tamanho da empresa representava alguma influência na natureza do trabalho gerencial. Usando o mesmo método de Mintzberg (1973), os autores acompanharam cada dirigentes participantes por dois dias completos de trabalho. Assim como Florén e Tell (2003), O'Gorman, Bourke e Murray (2005) chegaram a conclusão que o trabalho do dirigente da pequena empresa apresenta tanto aspectos semelhantes como diferentes do trabalho dos executivos, porém também não comenta quais aspectos predominam, quais as diferenças e porque elas ocorrem. $\mathrm{O}$ estudo carece de apresentação de conclusão sobre a variação da natureza do trabalho do dirigente, dependendo do contexto,.

No Brasil, poucas pesquisas foram feitas para avaliar a natureza do trabalho do dirigente da pequena empresa. Houve uma primeira tentativa no estudo de Gromik (2011) e, posteriormente, no estudo de Rosim (2013), que subsidia este artigo, onde os autores se propõem a validar a descrição de Mintzberg e sua aplicação para os dirigentes proprietários de pequenas empresas, por meio do estudo de dois casos de empresas localizadas no Estado de São Paulo.

\section{Método de Pesquisa}

Assim como no estudo de Mintzberg (1973), o método de coleta dados utilizado para os sete casos deste artigo foi a observação estruturada. Esse método foi escolhido por ser o mesmo adotado por outros autores da tradição em pesquisa do trabalho gerencial (FLOREN; TELL, 2012; KURKE; ALDRICH, 1983; O'GORMAN; BOURKE; MURRAY, 2005; TENGBLAD, 2006) e, desta forma, permitir a comparação entre as características dos estudos secundários também analisados neste artigo.

Os instrumentos de coleta de dados foram pré-planejados e um protocolo de observação estruturada foi organizado conforme o trabalho de Mintzberg (1973), sendo realizado, inclusive, um estudo piloto. Nesse protocolo foram registrados os tipos de atividades, as atividades, o tempo de duração, quem foram os participantes e se houve ou não agendamento. O trabalho de campo foi conduzido entre os anos de 2012 a 2017, sendo uma

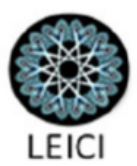


semana reservada a cada estudo de caso e, desta forma, a cada dirigente observado. No total foram observados cinco dirigentes.

Os demais dados da presentes pesquisa, que foram utilizados para comparação com os dados dos casos aqui estudados, são dados secundários extraídos dos estudos dos respectivos autores apresentados, a saber: Mintzberg (1973) para as grandes corporações; e Florén e Tell (2003) e O'Gorman; Bourke e Murray (2005) para as pequenas empresas de outros países.

Os critérios para a análise foram os mesmos adotados pelo estudo de Mintzberg (1973). Desta forma, para permitir comparações e igualar as métricas, todos os estudos comparados coletaram o tempo de início e fim de cada atividade e então realizou-se a análise dessas atividades pela comparação do tempo médio dispendido em cada uma delas.

A fim de justificar quando uma atividade foi considerada com o tempo médio dos executivos diferente do tempo médio dos dirigentes de pequenas empresas, utilizou-se o parâmetro de $10 \%$. Desta forma, toda atividade dos dirigentes da pequena empresa cujo tempo médio tinha uma diferença de $10 \%$ em relação ao tempo médio dos executivos, foi considerada diferente. O parâmetro de $10 \%$ foi adotado pois ele representa, no tempo médio da jornada diária, 48 minutos. Sendo uma das características do trabalho do administrador a brevidade, então em 48 minutos dá para se considerar uma diferença marcante na quantidade de atividades realizadas no dia.

Como forma de análise dos dados, os resultados foram organizados individualmente em uma planilha do software Microsoft Excel e, então, foram gerados gráficos de barras com a média de valor de cada categoria analisada, obtendo-se a média geral das horas das atividades de todos os indivíduos de cada categoria, a saber:

a) administrador das corporações;

b) dirigente das pequenas empresas de outros países; e

c) dirigentes das pequenas empresas brasileiras.

\section{Apresentação e Discussão dos Resultados}

A apresentação e discussão dos resultados deste artigo foram divididos em dois blocos principais. O primeiro bloco apresenta uma comparação das atividades dos executivos das corporações com as atividades dos dirigentes das pequenas empresas (tanto brasileiras quanto de outros países). O segundo bloco apresenta uma comparação das atividades dos dirigentes das pequenas empresas de outros países com dos dirigentes das pequenas empresas brasileiras.

\subsection{Os executivos das corporações e os dirigentes das pequenas empresas}

Antes de apresentar os dados das atividades, cabe apresentar aqui os resultados relativos à jornada de trabalho diária dos dirigentes pesquisados. Apesar de não ser considerada uma atividade, tal dado oferece parâmetros para que os demais dados sejam melhor compreendidos. A Figura 1 apresenta, em diferentes métricas, a quantidade de horas que os executivos e dirigentes trabalharam durante os dias em que foram observados. Percebe-se que que tanto os executivos das corporações como os dirigentes de pequenas empresas possuem, praticamente, a mesma jornada de trabalho. 
A semelhança desse dado permitiu que as conclusões nas demais atividades ficassem mais fáceis de serem interpretadas, uma vez que esse dado serviu de parâmetro para a análise e conclusão de outros, dentre eles, o que refere-se à quantidade de atividades realizadas no dia, apresentado na Figura 2.

Figura 1 - Jornada de trabalho

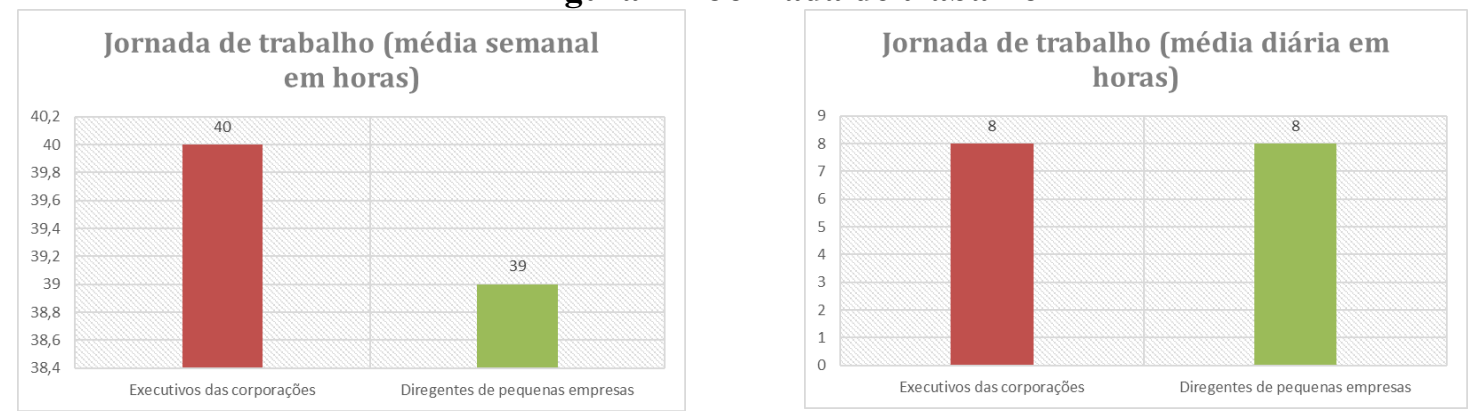

Figura 2 - Quantidade de atividade realizadas

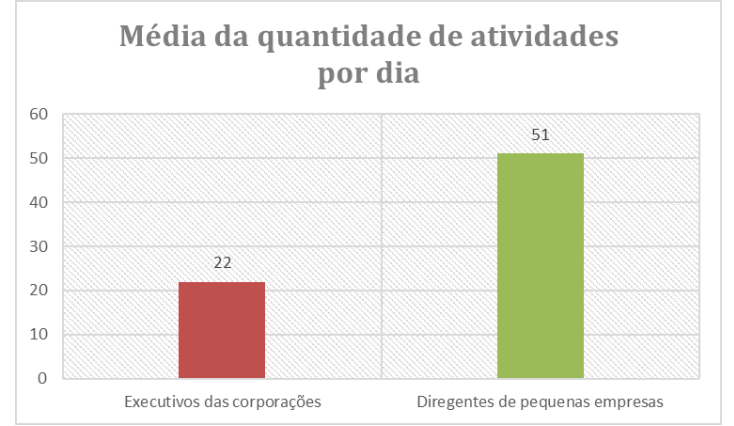

Apesar da jornada de trabalho dos executivos e dirigentes ter a mesma duração, o dirigente da pequena empresa realiza o dobro de atividades que os executivos das corporações. Aqui, se encontra uma diferença entre a natureza do trabalho do dirigente e a natureza do trabalho do executivo: a brevidade. Apesar de Mintzberg (1973) relatar a brevidade nas atividades dos executivos e confirma-las em pesquisas posteriores (MINTZBERG, 1994a; 2010), pode-se concluir que, a partir dos dados deste estudo, o trabalho do dirigente da pequena empresa se apresenta ainda mais breve e fragmentado do que o trabalho dos executivos. Tal fato se verifica pela realização de praticamente o dobro de atividades no mesmo intervalo de tempo.

A Figura 3 apresenta o tempo de duração de cada atividade, confirmando a primeira constatação deste artigo, de que as atividades do dirigente da pequena empresa são mais fragmentadas se comparadas com do executivo. Tal conclusão não discorda dos achados de Minztberg $(1973 ; 1975 ; 2010)$ sobre a brevidade do trabalho dos administradores, mas vai além, ao focar a pesquisa no campo específico das pequenas empresas e constatar que o trabalho do seu dirigente é ainda mais breve do que o trabalho dos executivos. Importante ressaltar que Mintzberg (1973) focou os seus estudos em executivos de empresas de médio para grande porte, por considera-los mais experientes. 
Figura 3 - Tempo de duração das atividades

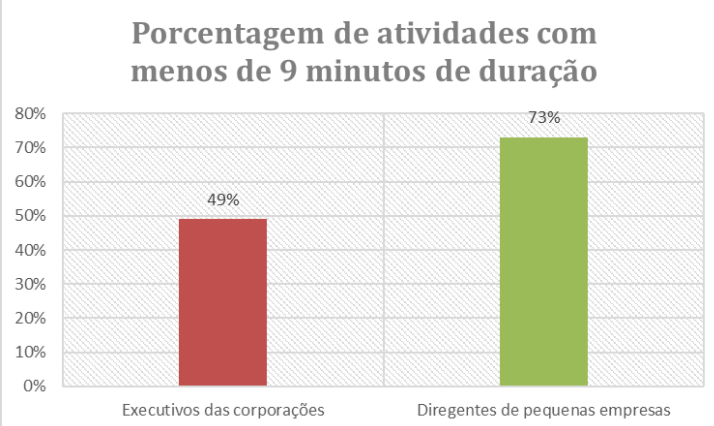

Porcentagem de ativividades com mais de 1 hora de duração

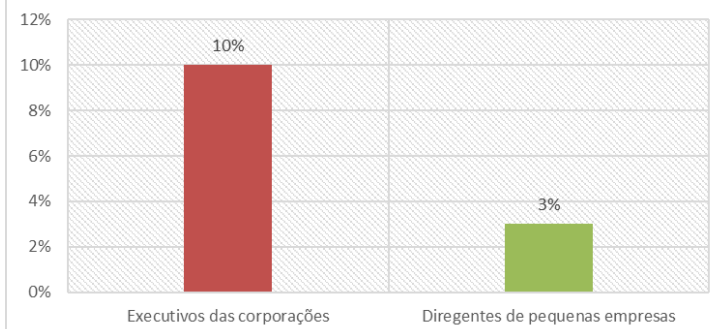

Indo um pouco além da brevidade, a Figura 4 apresenta as visitas internas e as atividades de mesa. As visitas internas se referem as atividades na qual os pesquisados estavam em movimento, ou seja, quando saiam da sua mesa de trabalho e faziam o que Minztberg (1973) coloca no seu estudo original como "tour". As atividades de mesa, por sua vez, são compreendidas como aquelas que o dirigente faz em sua sala, sentado na sua mesa de trabalho. Constata-se que o dirigente da pequena empresa faz mais essa atividade do que os executivos das corporações. Talvez seja porque ele é mais acionado em uma empresa de pequeno porte do que o executivo é solicitado nas grandes empresas. Tal fato pode ser explicado pela "proximidade hierárquica" pois esta apresenta a estrutura simples da pequena empresa como uma de suas especificidades de gestão.

Figura 4 - Local de realização das atividades

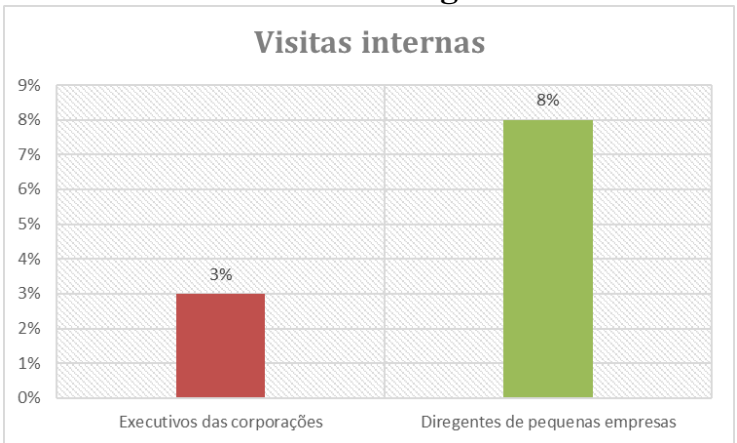

Atividades de mesa (porcentagem de tempo)

No entanto, o que se percebe ao analisar de forma mais holística a Figura 4, é que a diferença mencionada é pouco notável, não ultrapassando 5\%. Portanto, apesar da diferença existir, no decorrer da análise dos resultados se verifica que há outras atividades cujas diferenças são mais marcantes e que podem, efetivamente, levar a uma conclusão de que há poucas semelhanças entre o trabalho do executivo e o trabalho dos dirigentes. Nas atividades de mesa, os dados mostram a mesma tendência, de que as diferenças existem mas não são acentuadas a ponto de se afirmar que nesses aspectos o dirigente e o executivo trabalham de forma diferente. Isso demonstra que, tanto um quanto o outro, realizam mais atividades na sua sala do que movimentando-se pela empresa. Nos dirigentes, essa constatação é melhor compreendida por meio da "proximidade temporal" que apresenta como característica 
específica da pequena empresa a tomada de decisão dos dirigentes de forma mais intuitiva e, portanto, sem a dependência de informações e de modelos formais.

A Figura 5 indica, respectivamente, as reuniões que foram previamente agendadas e os contatos verbais; ou seja, o quanto se conversou com outras pessoas durante a jornada de trabalho. Conclui-se que o agendamento não é uma prática comum no cotidiano do dirigente da pequena empresa e é uma prática constante dos executivos uma vez que quase $60 \%$ do tempo é ocupado por reuniões agendadas. Muitos fatores podem explicar essa diferença e dentre eles, a existência de uma secretária contratada só para esse ofício. Também o fato do porte da empresa ser maior e, por consequência, a quantidade de funcionários que o executivo tem para se relacionar ser também maior e requerer portanto, um maior nível de organização do tempo.

Figura 5 - Formas de realização dos contatos
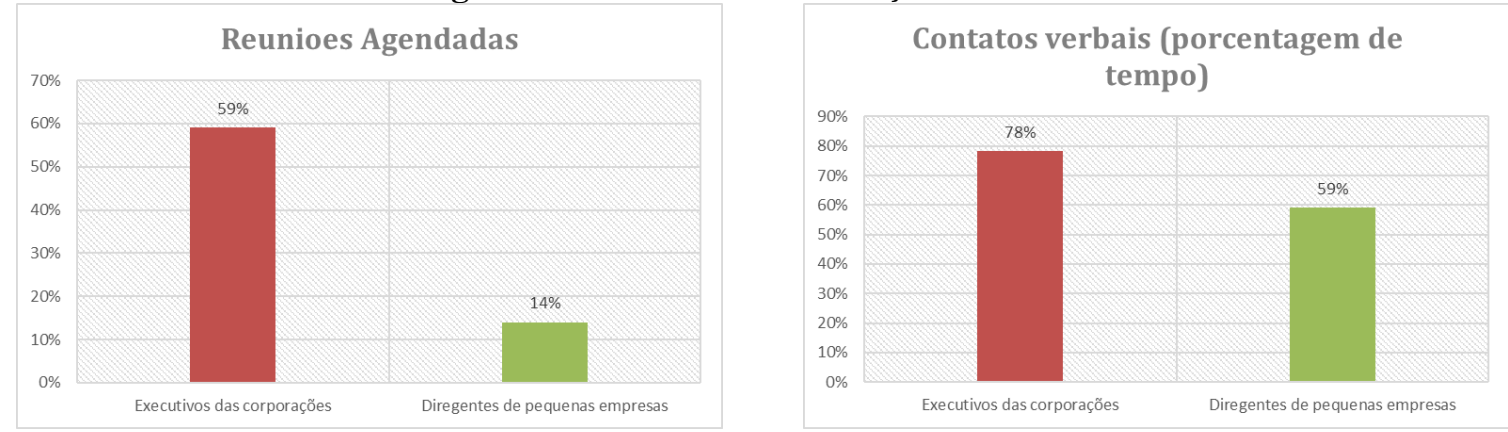

A proximidade hierárquica também explica a forma de contato na pequena empresa, decorrente da inexistência de áreas funcionais definidas, o que acaba concentrando toda a gestão na pessoa do dirigente. Isso faz com que, ao necessitar de uma informação financeira, por exemplo, o dirigente já consulte prontamente em seus registros, não havendo a necessidade de marcar uma reunião com setor financeiro para atualizá-lo da situação.

Quanto aos contatos verbais se percebe um dado que pode ser justificado a partir dos percentuais das reuniões agendadas; ou seja, o executivo além de ter mais funcionários para se relacionar e, por sua vez, conversar, ele também precisa recorrer a consulta de informações atualizadas o tempo todo para tomar decisões. Tal fato também foi reafirmado por Mintzberg (2013), quando ele menciona que os executivos orientam as ações dos funcionários com as informações que eles "coletam" no cotidiano do trabalho. O autor também confirma os achados de 1973 ao reafirmar os papeis de monitor, disseminador e porta voz da empresa, os quais os executivos tem que desempenhar constantemente (MINZTBERG, 1994a; 2010).

Já os dirigentes de pequena empresa, conforme mencionado acima, não tem que recorrer as informações que estão em poder de terceiros, uma vez que, ele é o grande concentrador das principais informações da empresa e, novamente aparece o papel da proximidade hierárquica e a proximidade temporal, indicando, respectivamente, a especificidade de personificação da gestão na pessoa do dirigente e a tomada de decisões de forma intuitiva. Um exemplo disso é que os indicadores para se manter o ponto de equilíbrio fica, muitas vezes, sendo monitorados pelo dirigente proprietário, de forma online, no seu computador e ele, dentre outras atividades que está realizando, fica conferindo como tais 
indicadores estão se desempenhando no decorrer do dia. Em uma grande empresa o executivo conta com áreas específicas para fazer tal tipo de controle.

As constatações anteriores se refletem também na Figura 6, que apresenta o executivo das corporações passando mais tempo com os subordinados do que o dirigente da pequena empresa. Apesar da diferença não ser muito ampla, a mesma ultrapassa 5\% e, acaba por ir de encontro a uma característica da pequena empresa que é muito retratada na literatura como um todo e reafirmada por Torrès (2004) como uma das especificidades de gestão relacionada a proximidade dos sistemas de informações: a informalidade das relações. Ressalta-se que não é só por esse indicador, de quanto tempo o dirigente passa com os subordinados, que tal informalidade nas pequenas empresas seja evidenciada, mas também por contrapor o fato da maioria dos livros usados nas escolas de administração apresentarem as corporações dotada de uma estrutura formalizada e com funções bem definidas.

\section{Figura 6 - Tempo gasto com pessoas}
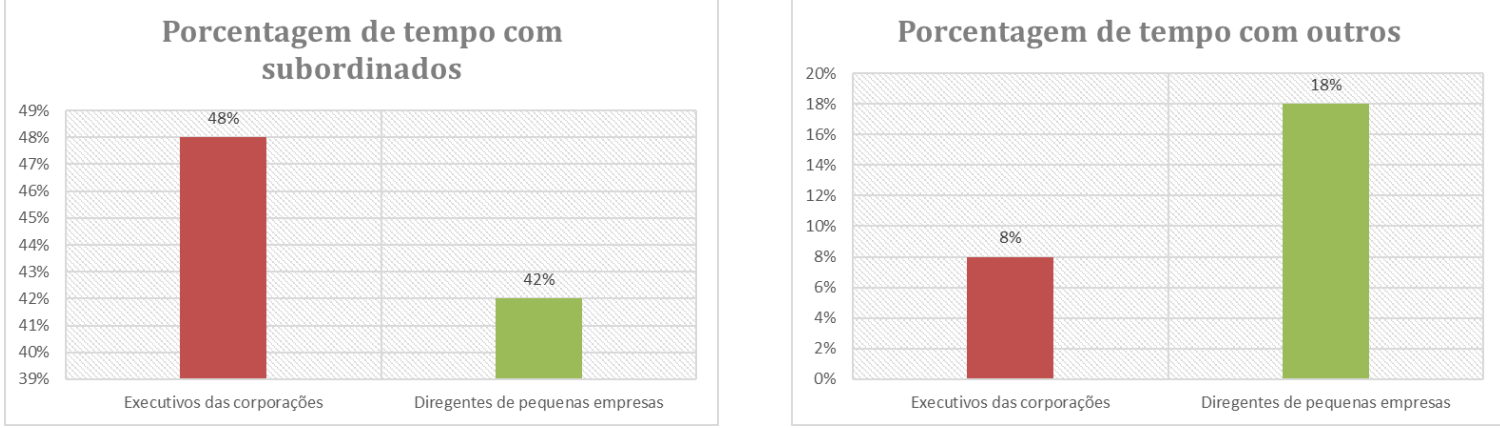

Importante destacar que o dirigente da pequena empresa apresenta mais contato com outras pessoas, que não os subordinados, clientes e fornecedores, do que o executivo. Essa constatação pode ser explicada por meio da especificidade da pequena empresa denominada "proximidade dos sistemas de informação" a qual tem como uma de suas características a proximidade física do dirigente proprietário com o mercado de atuação da empresa. Ou seja, na rotina diária do dirigente da pequena empresa ele atende e interage com pessoas que vão até a organização para falar com ele mas cujo assunto não necessariamente está relacionado ao negócio da empresa em si, mas sim ao que o negócio representa para a comunidade. $\mathrm{O}$ dirigente proprietário costuma atender pessoas da comunidade que vão procurar os mais diferentes tipos de coisas: emprego, vender rifas, pedir doações a instituições de caridade ou organizações sem fins lucrativos, patrocínio para times de futebol da cidade, dentre outros. Essa é, inclusive, uma demonstração do papel social e de desenvolvimento dos locais onde se instalam, que a pequena empresa realiza nas comunidades em que está inserida.

A Figura 7 mostra a quantidade de tempo que os investigados passam com os clientes e fornecedores. Um fator que pode explicar a diferença de tempo com clientes também se concentra na especificidade da proximidade dos sistemas de informações. $O$ fato da pequena empresa muitas vezes estar situada na comunidade que consome os seus produtos, faz com que a facilidade de acesso ao dirigente por parte dos clientes seja mais fácil. Já nas corporações há um departamento específico para esse fim. Até mesmo para realizar a venda dos produtos tem o departamento específico de vendas. Na pequena empresa essa parte de 
vendas é, na maioria das vezes, realizada pelo próprio dirigente, pois ele é a garantia do negócio e até mesmo do produto a ser comercializado.

Figura 7 - Tempo gasto com clientes e fornecedores
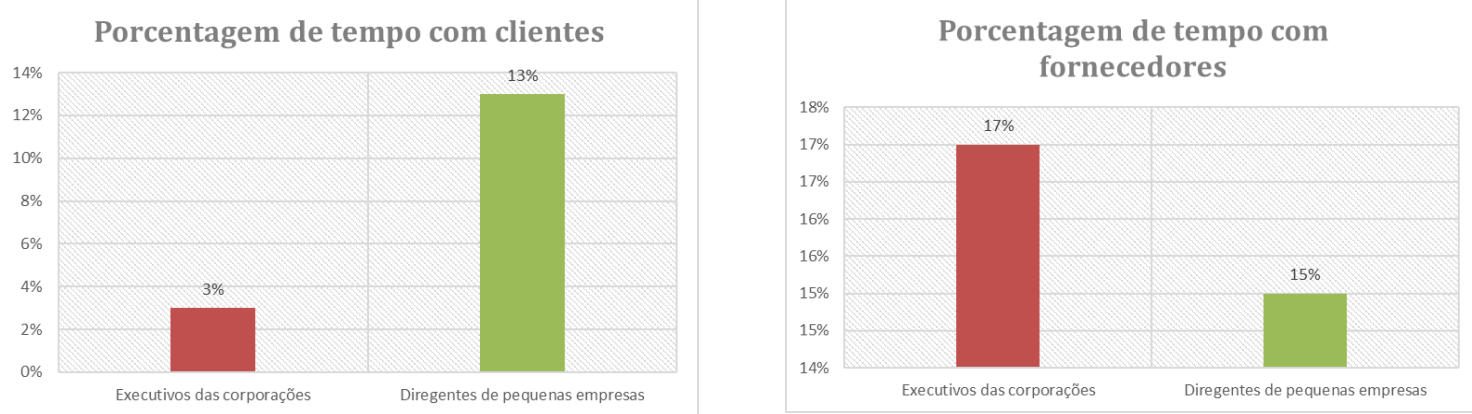

Quanto ao tempo com fornecedores não foi identificada uma diferença notável. O fato da grande empresa possuir maior quantidade de fornecedores e passar o mesmo tempo com eles do que um dirigente, já altera a percepção acerca do dado analisado. Isso se torna compreensível pela dependência da pequena empresa em relação aos seus fornecedores, pois o preço que a pequena empresa paga em um insumo pode desestabilizar todas suas finanças e parar a produção. Já o executivo das corporações tem poder de barganha com os fornecedores por ter grande escala. Isso facilita as negociações e faz com que eles deleguem com mais facilidade essa atividade para um setor específico.

\subsection{Os dirigentes das pequenas empresas do Brasil e os dirigentes das empresas de outros países}

A fim de compreender melhor a natureza do trabalho do dirigente brasileiro e comparar com os dirigentes de outros países, o artigo apresenta nesta seção os dados dessas duas categorias (dirigentes brasileiros e de outros países) separadamente. Os únicos dados não apresentados serão os referentes a "atividades com menos de 9 minutos de duração" e "atividades com mais de uma hora de duração". Tais dados não serão apresentados porque o estudo de O'Gormam, Bourke e Murray (2005), que se refere as pequenas empresas internacionais, não apresentou tal dado.

Vale ressaltar que trata-se de uma comparação para verificar a natureza do trabalho do dirigente e, não necessariamente, servir de guia para indicar o que o dirigente da pequena empresa brasileira deve fazer ou não, comparado aos demais. Isso porque, tanto para esta comparação, quanto para a comparação da subseção anterior (entre executivos e dirigentes), deve-se respeitar e compreender a interferência de outras variáveis que podem justificar a forma de conduzir a empresa. Como exemplo, cita-se a cultura de um país em relação a cultura de outro ou as individualidades legais de cada país, que muitas vezes interferem no contexto das empresas.

A Figura 8 apresenta dados comparativos da jornada de trabalho de dirigente de outros países de do Brasil. Percebe-se que a jornada de trabalho dos dirigentes brasileiros e a de outros países praticamente não apresentam diferença. No entanto, de acordo com o encontrado nesse estudo, os dirigentes de outros países tem a jornada de trabalho um pouco mais extensa do que os brasileiros. Já na quantidade de atividades realizadas por dia se 
verifica o movimento contrário, ou seja, os dirigentes brasileiros realizam mais atividades por dia do que os dirigentes dos outros países. Desta forma, conclui-se que o trabalho dos dirigentes brasileiros, de acordo com os achados deste artigo, é ainda mais fragmentado e, por sua vez, breve do que o trabalho dos executivos e do que o trabalho dos dirigentes internacionais.

Figura 8 - Jornada de trabalho dirigentes de pequenas empresas

Jornada de trabalho (média semanal em horas)

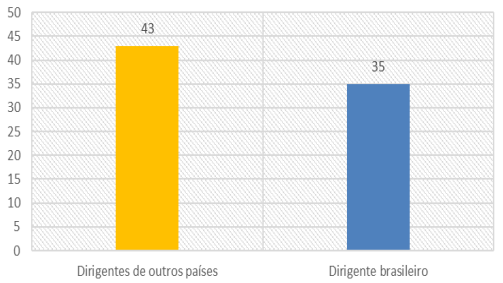

Jornada de trabalho (média diária em. horas)

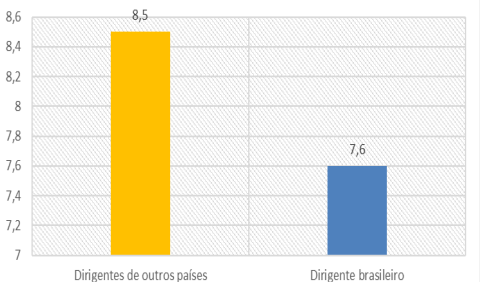

Média da quantidade de atividades por dia

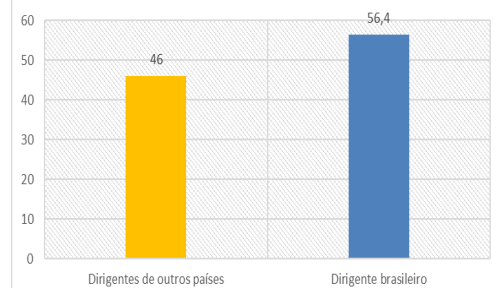

Conforme mostrado na Figura 9, as visitas internas tem praticamente o mesmo percentual, pois a diferença apresentada não é expressiva. Isso indica que tais dirigentes não se movimentam muito pela empresa durante a jornada de trabalho mas fazem bastante atividades de mesa como checar e-mails, atender telefonemas e analisar dados. Uma explicação para esse tipo de comportamento dos dirigentes é apresentada por Oliveira et al. (2015). Nesse estudo os autores dizem que a movimentação do dirigente da pequena empresa não pode ser considerada da mesma natureza da movimentação (visita interna) do dirigente, uma vez que quando o executivo faz essa atividade ele está focado em alimentar sua rede de contato e informações. Já o dirigente da pequena empresa, muitas vezes anda pela empresa por questões operacionais, como por exemplo, consertar uma máquina.

Figura 9 - Local de realização das atividades

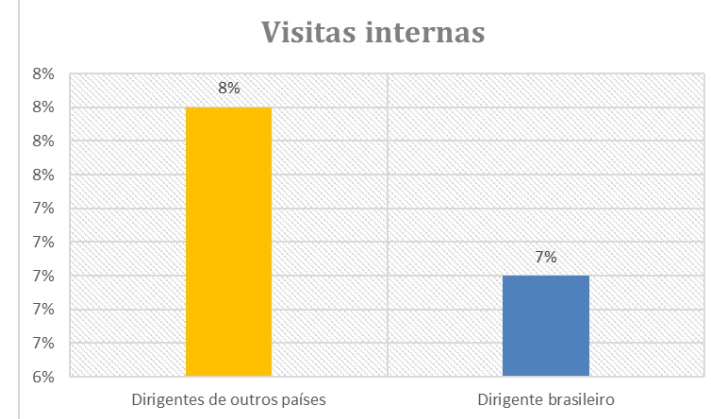

Atividades de mesa (porcentagem de tempo)

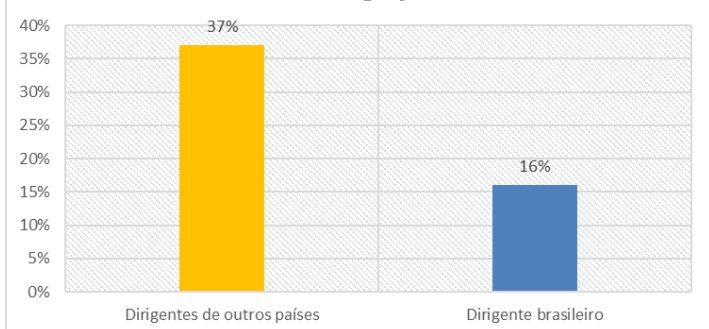

Vale ressaltar que o estudo de Oliveira et al. (2015) foi realizado com uma amostra de 70 dirigentes proprietários de pequenas empresas brasileiras, assim suas conclusões podem ser aplicadas na explicação de algumas diferenças da natureza do trabalho do dirigente brasileiro em relação a natureza do trabalho dos dirigentes de outros países. Outra constatação da Figura 9 é a de que os dirigentes de outros países realizam mais atividades de mesa do que os brasileiros e isso pode ser explicado pela centralização da gestão mencionada por Torrès (2004). Desta forma, sendo uma especificidade dos dirigentes ser centralizadores, entende-se

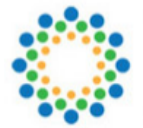


os dirigentes de pequenas empresas de outros países ainda mais centralizadores do que os brasileiros.

Em comparação com os executivos de Mintzberg (1973), no que se refere as visitas internas, ambos dirigentes (de outro países e brasileiros) realizam mais esta atividade. Já nas atividades de mesa, os dirigentes brasileiros se aproximam mais do percentual dos executivos do que os dirigentes de outros países, ou seja, tanto os dirigentes brasileiros quanto os executivos de Minztberg (1973) tem evidências de serem menos centralizadores das decisões.

Por meio da Figura 10 se verifica que os dirigentes de outros países dão preferência para os contatos verbais e para as reuniões agendadas, assim como os executivos observados por Mintzberg (1973). Os brasileiros também fazem bastante contatos verbais, , afinal, passam 54\% do tempo fazendo esse tipo de contato, no entanto, os dirigentes internacionais e executivos das corporações fazem ainda mais uso dessa atividade para atingir os objetivos do negócio. Além disso, há indicações claras que os dirigentes brasileiros não agendam reuniões, sendo que só passam $8 \%$ do tempo nesse tipo de atividade contra $20 \%$ dos dirigentes de outros países.

\section{Figura 10 - Formas de realização dos contatos}
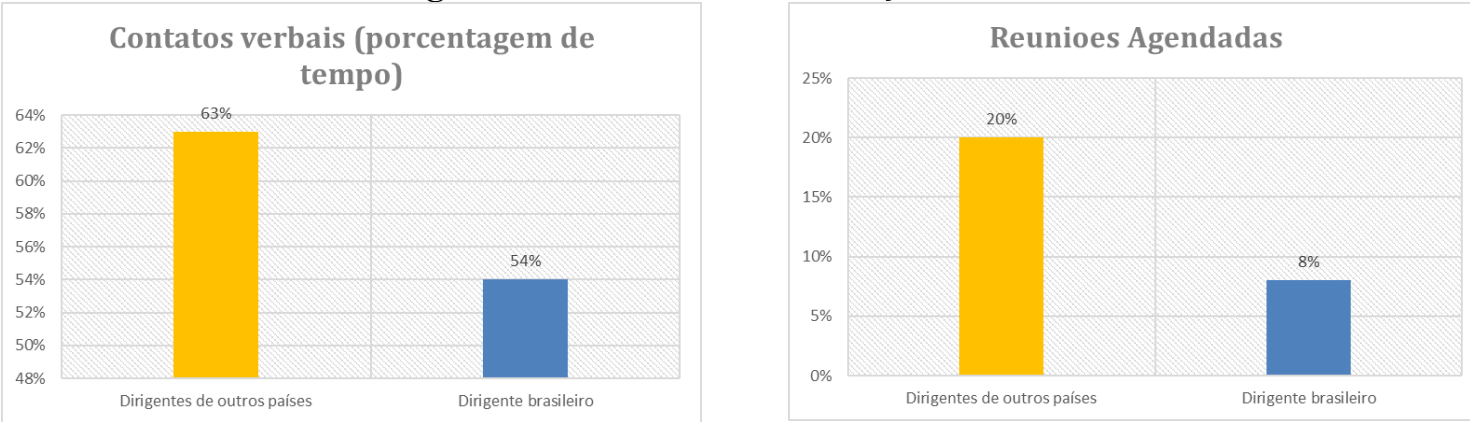

A Figura 11 apresenta o percentual de tempo que os dirigentes passam com subordinados e com outras pessoas que não necessariamente são da empresa. Percebe-se que os dirigentes de outros países passam mais tempo com subordinados do que os dirigentes brasileiros. Tal diferença é expressiva e na mesma tendência do trabalho dos executivos, o que indica que, também nesse quesito o trabalho dos dirigentes de outros países se assemelha mais com o trabalho dos executivos, cujo resultado foi de $48 \%$, do que com os dirigentes brasileiros.

\section{Figura 11 - Tempo gasto com pessoas}
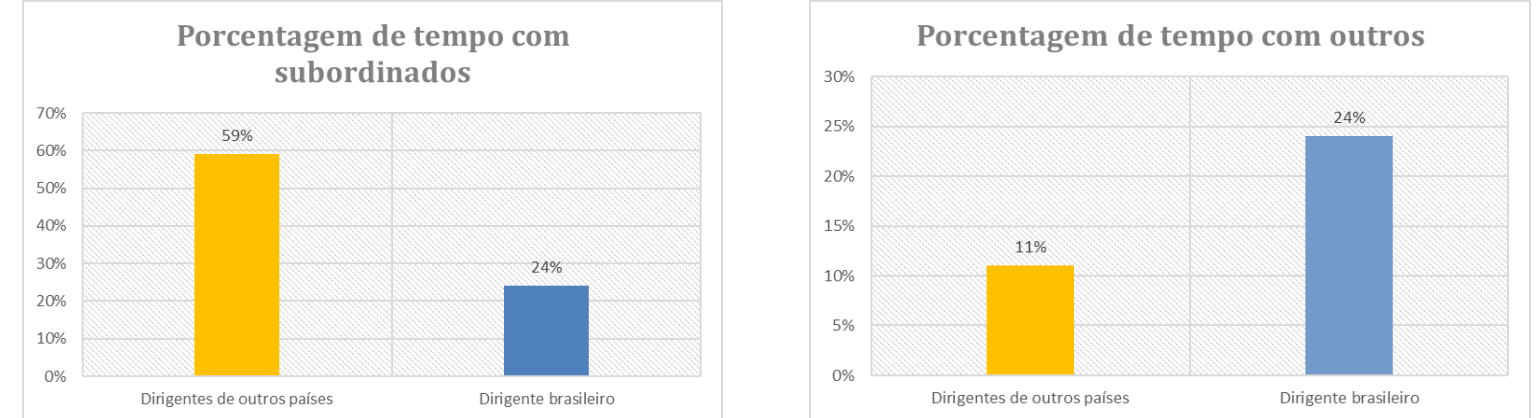
O estudo de Oliveira et al. (2015) aponta que os dirigentes brasileiros, ao passar tempo com os subordinados, estão mais preocupados em passar orientações técnicas para a realização de atividades do que preocupar-se ou ocupar-se de entender aspectos sociais e motivacionais de tais funcionários. Também na porcentagem de tempo com outros, os dirigentes de outros países se aproximam do dado dos executivos, que foi $8 \%$. Isso indica que o dirigente brasileiro é o que mais se relaciona com outras pessoas que não são clientes, subordinados ou fornecedores. Isso ocorre porque o papel de relações públicas do dirigente da pequena empresa é relacionado a sua postura de fazer uma rede de contatos externas a pequena empresa. Isto está relacionado com o fato do dirigente entender a necessidade de se comunicar e defender questões relevantes da comunidade na qual a pequena empresa está inserida (OLIVEIRA et al., 2015).

A Figura 12 apresenta a porcentagem de tempo com fornecedores e com clientes.

Figura 12 - Tempo gasto com clientes e fornecedores
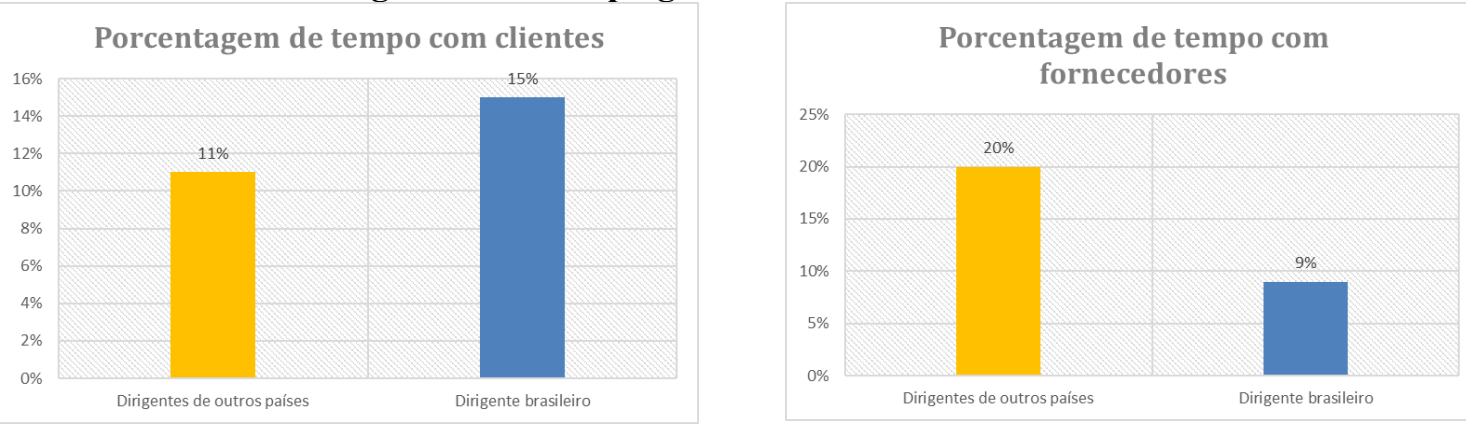

Em relação ao tempo gasto com clientes, não se verifica uma grande diferença entre as duas categorias. Em relação aos executivos analisados por Mintzberg (1973), ambos dirigentes (brasileiros ou de outros países), se diferenciam pois passam dos $10 \%$ do tempo com clientes, enquanto que os executivos não atingem 5\% de tempo da jornada de trabalho com clientes. $\mathrm{O}$ fato dos dirigentes brasileiros se ocuparem mais dessa atividade de contato com os clientes também pode ser explicado pelo trabalho de Oliveira et al. (2015), ao mencionam que na pequena empresa a estruturação de atividades geralmente só ocorre para atender as necessidades do cliente e, desta maneira, atingir as aspirações comerciais. Tal conclusão elucida ainda mais a preocupação e prioridade que os dirigentes brasileiros dão aos seus clientes.

Já em referência ao tempo que passam com os fornecedores, a diferença é mais notável entre os dirigentes brasileiros e de outros países, sendo de $11 \%$. Em relação a esse tempo, os dirigentes de outros países praticamente se igualam aos executivos de Mintzberg (1973), com 17\%, enquanto que os brasileiros despendem menos de $10 \%$ do tempo. Tal fato pode indicar uma maior preocupação com custos ou dependência financeira dos dirigentes de outros países. Também pode estar relacionado com normatizações e garantias de procedência, tal como as normas ISO. Dependendo do que a pequena empresa produz, ela necessariamente tem que se certificar da origem do seu insumo sob pena de não conseguir comercializar o seu produto. Percebe-se então que tal fato, aliado a negociação de valores e custos, pode estar ocupando mais tempo dos dirigentes de outros países do que o tempo dos dirigentes brasileiros. 


\section{Considerações Finais}

A fim de responder se o trabalho do dirigente da pequena empresa apresenta mais aspectos similares ou diferentes do trabalho do executivo, apresenta-se então as principais conclusões da análise dos dados deste estudo:

- que o trabalho do dirigente da pequena empresa apresenta mais aspectos similares ao trabalho do executivo das corporações, diferenciando-se no que se refere a brevidade e fragmentação das atividades e preferência por não agendamentos e improvisos; e

- $\quad$ em comparação com dirigentes internacionais, o trabalho do dirigente da pequena empresa brasileiro acentua mais as diferenças mencionadas acima enquanto que o trabalho do dirigente das pequenas empresas internacionais se aproxima mais do trabalho dos executivos.

De acordo com os achados, uma proposta de descrição para o trabalho do dirigente da pequena empresa se resume a dizer que ele tem preferência por atividades mais rápidas e curtas, não agendadas e, portanto, de forma improvisada, dedica muito do seu tempo a pessoas que não necessariamente são seus funcionários ou tem uma relação direta como o negócio principal da empresa.

Embora o artigo contribua para a discussão sobre o desenvolvimento de uma teoria específica da pequena empresa, especialmente ligada ao trabalho de seu dirigente, é preciso considerar as limitações da pesquisa. Destaca-se o grau de subjetividade presente, advindos da presença do pesquisador durante a coleta de dados, podendo acarretar mudança na atitude dos dirigentes estudados. Além disso, a amostra reduzida do estudo de caso, inclusive no espaço físico não permite extrapolar os achados.

Para futuras pesquisas outros contextos organizacionais podem ser incluídos e novas ferramentas de coleta de dados utilizadas, permitindo ganhos no tamanho da amostra e agilidade na análise e tratamento dos dados.

\section{Referências}

ADAMS, J. H.; KHOJA, F. M.; KAUFFMAN, R. Relationships within small business organizations. Journal of Small Business Management, v. 50, n. 1, p. 20-40, 2012.

ALBUQUERQUE, A. F. et al. A change in the importance of mortality factors throughtout the life cycle stages of small businesses. Journal of Global Entrepreneurship Research, v. 6, n. 8, p. 1-18, 2016.

AREND, R. J. Entrepreneurship and dynamic capabilities: how firm age and size affect the "capability enhancement-SME performance" relationship. Small Business Economics, v. 42, n. 1, p. 33-57, 2014.

ANDERSSON, S.; FLÓREN, H. Differences in managerial behaviour between small international and non international firms. Journal International Enterpreneurship, n. 9, p. 233-258, 2011.

ANDERSSON, S.; TELL, J. The relationship between the manager and growth in small firms. Journal of Small Business and Enterprise Development, v. 16, n. 4, p. 586-598, 2009.
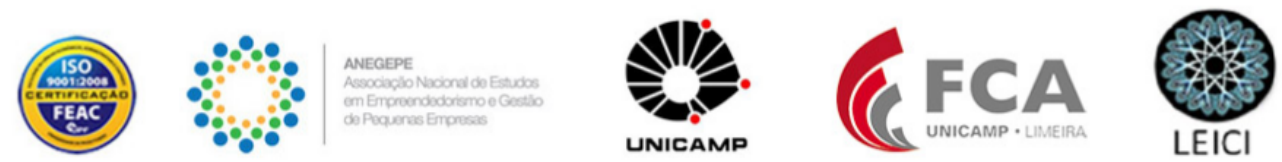
BOSWELL, J. The rise and decline of small firms (Routledge Revivals). New York: Routledge, 2014. 272 p.

BRUCE, D. et al. (Small) business activity and state economic growth: Does size matter? Regional Studies, v. 43, p. 229-245, 2009.

CARLSON, S. Executive behaviour. Stockholm: Strombergs, 1951.

COPPA, M.; SRIRAMESH, K. Corporate social responsibility among SMEs in Italy. Public Relations Review, v. 39, p. 30-39, 2013.

DANDRIDGE, T. C. Children are not "little grown-ups": small business needs its own organizational theory. Journal of Small Business Management, v. 17. p. 53-57, 1979.

DIETRICH, A. Explaining loan rate differentials between small and large companies: evidence from Switzerland. Small Business Economics, v. 38, n. 4, p. 481-494, 2012.

ESCRIVÃO FILHO, E. Pequena empresa e administração estratégica: reconhecendo especificidades, restrições e facilitadores com o mapa organizacional. 2006. Tese (LivreDocência). Escola de Engenharia de São Carlos da Universidade de São Paulo - EESC/USP.

ESCRIVÃO FILHO, E.; MENDES, J. V. O trabalho do administrador: uma visao geral e crítica. In: ESCRIVÃO FILHO, E.; PERUSSI FILHO, S. (orgs.). Teorias de administração: introdução ao estudo do trabalho do administrador. São Paulo: Saraiva, 2010. Cap. 2, p. 35-54.

ESCRIVÃO FILHO, E. et al. Identifying SME mortality factors in the life cycle stages: an empirical approach of relevant factors for small business owner-managers in Brazil. Journal of Global Entrepreneurship Research, v. 7, n. 5, p. 1-15, 2017.

FLORÉN, H.; TELL, J. What do owner-managers in small firms really do? Replicationg Choran, Mintzberg and Kurk \& Aldrich. Proceedings 16th Annual Conference of Small Enterpise Association of Australia and New Zealand, 2003.

. Managerial Behaviour in Slow and Fast Growing Small Firms. Research on Technology, Innovation and Marketing Management, 2007. 16 p. Disponível em: $<$ https://www.researchgate.net/publication/229003957_Managerial_behavior_in_slow_and_fa st_growing_small_firms $>$. Acesso em: 16 mar. 2018.

Managerial behavior in small firms: does it matter what managers do? In: TENGBLAD, S. (ed.). The work of managers: towards a practice theory of management. Oxford: Oxford University Press, 2012. Cap. 13, p. 245-263.

FULLER-LOVE, N. Management development in small firms. International Journal of Management Reviews, v. 8, n. 3, p. 175-190, 2006.

GABRIELSSON, J.; TELL, J. Managerial learning and development in small firms: implications based on observations of managerial work. Report. Lund, 2009. (CIRCLE Eletronic Working Paper Series, paper n. 2009/03).

GROMIK, S. R. Análise das atividades do dirigente da pequena empresa: estudo baseado nos conceitos de Mintzberg sobre o trabalho do administrador. 2011. Dissertação (Mestrado). Escola de Engenharia de São Carlos da Universidade de São Paulo - EESC/USP. JULIEN, P. A. Small Businesses as a research subject: some reflections on knowledge of small business and its effects on economic-theory. Small Business Economics. v. 5. p. 157$166,1993$.

KURKE, L. B.; ALDRICH, H. E. Mintzberg was right! A replication and extension of the nature of managerial work. Management Science, v. 29, n. 8, p. 975-984, 1983.

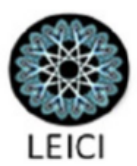


LEONE, N. M. C. P. G. As especificidades das pequenas e médias empresas. Revista de Administração, v. 34, n. 2, p. 91-94, 1999.

MINTZBERG, H. The nature of managerial work. New York: Harper \& Row, 1973. 298 p. 1975. . Managers job - folklore and fact. Harvard Business Review, v. 53, n. 4, p. 49-61, 26, 1994a.

Rouding out the manager's job. MIT Sloan Management Review, v. 36, n. 1, p. 11. Rethinking strategic planning part II: new roles for planners. Long Range Planning, v. 27, n. 3, p. 22-30, 1994 b.

Managing: desvendando o dia a dia da gestão. Porto Alegre: Bookman, 2010. 304 p. O'GORMAN, C.; BOURKE, S.; MURRAY, J. A. The nature of managerial work in small growth-orientated businesses. Small Business Economics, v. 25, p. 1-16, 2005.

OLIVEIRA, J. de. et al. What do small business owner-managers do? A managerial work perspective. Journal of Global Entrepreneurship Research, v. 5, n. 19, p. 1-21. 2015.

OLSEN, K.; LEGG, S.; HASLE, P. How to use programme theory to evaluate the effectiveness of schemes designed to improve the work environment in small businesses. Work, v. 41, p. 5999-6006, 2012.

ROSIM, D. Trabalho do dirigente da pequena empresa: estudos de caso em empresas do setor metal mecânico. 2013. Dissertação (Mestrado). Escola de Engenharia de São Carlos da Universidade de São Paulo - EESC/USP.

SIMARD, C.; RICE, R. E. Managerial information behaviour: relationships among total quality management orientation, information use environments, and managerial roles. Total Quality Management \& Business Excellence, v. 17, n. 1, p. 79-95, 2006.

STEWART, R. To understand the manager's job: consider demands, constraints, choices. Organizational Dynamics, v. 4, n. 4, p. 22-32, 1976.

Research Managerial agendas - reactive or proactive? Organizational Dynamics, v. 8, n. 2, p. 34-47, 1979.

TELL, J.; GABRIELSSON, J. Management development in small firms: understanding the learning dilemma for small business managers. International Journal of Innovation Science, v.5, n. 3, p. 143-152, 2013.

TENGBLAD, S. Is there a 'new managerial work'? A comparison with Henry Mintzberg's classic study 30 years later. Journal of Management Studies, v. 43, n. 7, p. 1437-1461, 2006.

TENGBLAD, S.; VIE, O. E. Management in practice: overview of classic studies on managerial work In: TENGBLAD, S. (Org.) The work of managers: toward a practice theory of management. New York: Oxford University Press, 2012.

TONIDANDEL, S.; BRADDY, P. W.; FLEENOR, J. W. Relative importance of managerial skills for predicting effectiveness. Journal of Managerial Psychology, v. 27, n. 6, p. 636$655,2012$.

TORRÈS, O. The SME concept of Pierre-André Julien: an analysis in terms of proximity.

Picola Impresa/Small Business, v. 17(2), p. 51-62, 2004. Disponível em:

$<$ http://oliviertorres.net/travaux/pdf/TORRESINGL.pdf>. Acesso em: 3 mai. 2015.

WELSH, J. A; WHITE, J. F. A small business is not a little big business. Harvard Business Review, v. 59. p. 18-\&, 1981. 